\title{
Active thermography evaluation of bonding defects in adhered ceramic tiling: thermal stimulation conditions and data analysis methods assessment
}

\author{
by N. Simões ${ }^{*, * *}$, J. Laranjeira* ${ }^{*}$ I. Simões ${ }^{*}$, A. Tadeu ${ }^{*, * *}$ and C. Serra ${ }^{*, * *}$ \\ ${ }^{*}$ CICC, Department of Civil Engineering, University of Coimbra, Pólo II, Rua Luís Reis Santos, 3030-788 \\ Coimbra, Portugal, \{nasimoes, joao.laranjeira, mivsimoes, tadeu, cserra\}@itecons.uc.pt \\ **ITeCons - Instituto de Investigação e Desenvolvimento Tecnológico em Ciências da Construção, Rua Pedro \\ Hispano, 3030-289 Coimbra, Portugal
}

\begin{abstract}
Bonding defects in adhered ceramic tiling systems are common building pathologies that should be identified at an early stage. Active thermography technique is a diagnostic tool that may be explored to detect those bonding defects and that can also provide accurate information for its maintenance and repair. However, when applied to civil engineering, a wide range of parameters associated with the application of an external heating source may be involved. This paper intends to determine the feasibility of using the active thermography technique to detect and characterize bonding defects in adhered ceramic tiling and to propose an experimental procedure. For this purpose, an experimental assessment of different thermal stimulation conditions is carried out (i.e. number of heating periods, heating time and the available heating power) for an optical heat source. Additionally, the data analysis methods available in a specific software (Automation Technology software) are evaluated, in order to establish an effective and efficient experimental procedure. In order to accomplish this, a set of test specimens, with artificial defects of various materials with different dimensions and depths within the adhesive layer, was performed. The test specimens were subjected to various thermal stimulation conditions and the resulting raw thermal images were processed with the data analysis methods available in the software.
\end{abstract}

\section{Introduction}

Active infrared (IR) thermography is a reliable non-destructive and non-contact evaluation technique applied to a wide variety of fields, and in particular to civil engineering. This technique involves the application of thermal stimulation to the surface of a material or structure under inspection using an external heat source, and the recording of the resulting thermal patterns using an IR imaging instrument, such as an IR camera.

The application of an external heat source will heat up the material or structure surface by releasing thermal waves (i.e. thermal radiation) that will penetrate and propagate inside it by diffusion, depending on its thermal properties (i.e. thermal conductivity, specific heat capacity and apparent density [1],[2]) and its internal layers. The presence of a defect (i.e. voids, pores, or delaminations) at a certain depth interferes with the heat flow causing local surface temperature variations. The transient thermal gradient generated will affect the surface temperature distribution as a function of time. However, cracks oriented perpendicular to the inspected surface will have no effect on the heat flow, and will not be detected, since when the heat flux is applied perpendicular to the surface, it is only possible to detect changes in the thermal properties normal to the surface [3]. One the other hand, since the surface temperature of the material or structure under inspection is related to their thermal radiation emitted [4], the use of an IR camera enables the detection of the thermal radiation emitted from the surface, based on the Stefan-Boltzmann law [5]. In this context, the use of an IR camera to record surface temperature changes over time enables defect detectability and characterization (i.e. size, depth, and/or thermal properties [6]). It displays an IR images sequence (i.e. thermograms), each one composed with a pixel array with different shades of colors, or a gray scale, corresponding to various temperature levels.

Nevertheless, because active thermography requires the application of an external heating source to produce an additional thermal stimulation on the material surface, several characteristics of construction materials and massive structures may lead to problems. Building materials often have relative low thermal diffusivities (e.g. concrete and plaster compared to metals), requiring a very large response time for heating up and cooling down processes, since response time to temperature changes on the surface under inspection depends on the materials thermal diffusivity [7]. Moreover, the use of active thermography, although applicable in buildings [8], is affected by environmental conditions. The most important environmental conditions that strongly affects IR images acquisition and interpretation are direct or indirect sun radiation, wind with a varying speed, and moisture, e.g. from rain [2]. Furthermore, heterogeneous surface characteristics, such as texture, roughness, color, and dirt ([1],[2],[7]), tend to decreasing the signal-to-noise ratio (SNR) by heterogeneous emissivity [7]. Buildings and civil structures inspection with active thermography technique can also be challenging due to the sheer size of large structural elements and the fact that defects that can be fairly deep inside the material [7]. 
In order to overcome the restrictions that active thermography technique poses in such cases, there are various methods available for thermal stimulation ([1],[6],[9]) and for data analysis of the resulting raw thermal images ([6],[7],[10]).

The thermal stimulation method employed in each situation depends on the thermal waveforms that are released by the external heat source over to the surface [6], either in a modulated continuous form (sinusoidal or rectangular) or via pulses (short rectangular or other shaped pulses [2]). Table 1 presents a classification of thermal stimulation methods according to thermal waveform. Other classifications may be found in the literature [9], i.e. lock-in repetitive, pulse flash (for milliseconds) and pulse transient (between seconds to minutes). Thermal stimulation methods may also be categorized according to the type of energy source being used, such as optical (e.g. photographic flashes, halogen lamps, IR lamps), ultrasound, inductive (e.g. eddy current). In this way, in order to avoid confusion, as a result of the terminology used, the thermal waveform and the type of energy source shall be used to classify thermal stimulation methods [6].

Table 1. Classifications of thermal waveforms and thermal stimulation methods for active infrared (IR) thermography technique (adapted from [1],[6],[9]).

\begin{tabular}{|c|c|c|c|}
\hline \multicolumn{2}{|c|}{ Thermal waveform and source duration } & State & $\begin{array}{c}\text { Thermal stimulation } \\
\text { method }\end{array}$ \\
\hline Modulated & $\begin{array}{c}\text { Thermal waves modulated (sinusoidal or } \\
\text { rectangular) at a given frequency (0,01 Hz } \\
\text { to 20 Hz), from seconds to hours }\end{array}$ & $\begin{array}{c}\text { Require several cycles to } \\
\text { reach a steady state }\end{array}$ & Lock-in thermography (LT) \\
\hline Pulse & $\begin{array}{c}\text { Short pulse of a few milliseconds for } \\
\text { high-conductivity materials (i.e. metal) to a } \\
\text { few seconds for low-conductivity materials }\end{array}$ & Transient state & Pulsed thermography (PT) \\
\hline $\begin{array}{c}\text { Square } \\
\text { pulse }\end{array}$ & Long pulse of several seconds or minutes & Transient state & $\begin{array}{c}\text { Square pulse } \\
\text { thermography (SPT) }\end{array}$ \\
\hline Step & $\begin{array}{c}\text { Continuous heating from a few to several } \\
\text { seconds }\end{array}$ & Transient state & $\begin{array}{c}\text { Step heating } \\
\text { thermography (SHT) or } \\
\text { stepped heating pulse } \\
\text { (SH) (i.e. long pulse) }\end{array}$ \\
\hline
\end{tabular}

The thermal stimulation methods that have been proposed over the years (table 1) are based on two classic ones: lock-in thermography (LT) and pulsed thermography (PT). In LT, the application of a periodical heating process, by releasing modulated thermal waves at a given frequency to the surface under inspection, may allow defect detection at a certain range depth, depending on the propagation frequency of thermal waves ([1],[2]). In this context, low-frequency thermal waves will penetrate deeper into the material or structure than the high-frequency waves, since the main characteristic of thermal waves is the strong decay (that can be characterized by the thermal diffusion length), as a function of depth [2]. The thermal diffusion length depends on the thermal diffusivity and the frequency of the thermal wave [2]. Based on Fourier transform, the recorded temperature information (for each pixel of the IR images sequence) is transformed into the frequency domain, resulting in phase and amplitude images [9]. Phase image analysis stands out, since it is not sensitive to sun radiation, reflections, dirt, and heterogeneous emissivity [9]. In contrast to LT, with PT thermal waves with several frequencies are simultaneous released to the inspected surface, by a heating pulse [1]. In some situations, a cooling source may be used [1]. Depending on defect depth, the thermal patterns obtained will diverge at a given time, allowing defect detection.

Several signal processing methods have been developed or adapted from other fields to process the resulting raw thermal images, in order to improve the SNR, increase defect contrast and/or characterize defects [6]. The pulse phase thermography (PPT) method stands out, as it resulted from the combination of the advantages of LT and PT methods ([1],[2],[7]). Time-frequency duality is the basis of PPT method and it consists in stimulating the surface under inspection by releasing thermal waves with different propagation frequencies. Then, the recorded temperature information is transformed into the frequency domain, by extracting the various frequencies with one-dimensional Fourier transform on each pixel of the IR images sequence ([1],[2],[9]). The extraction is performed with very short computing times [9]. The main advantages of PPT results from phase images, as they are less influenced by surface characteristics, less sensitive to non-uniform heating, and they allow to have a deeper probing and thus enhanced defect detectability. Defect geometry resolution is also enhanced. Finally, phase images do not require previous knowledge of sound areas, as it is required in simple thermal contrast processing [7]. Arndt [7] reported that data processing through PPT method application is an adequate approach for active thermography in the civil engineering field, particularly if combined with long heating pulses and cooling down process. Nevertheless, it is helpful to have the possibility of using several signal processing methods to analyse an IR image sequence, and then chose the best for a given IR measurement test [9].

When using active IR thermography, defect detectability will depend on several factors, such as defect geometry (area and thickness) and depth, thermal properties of a defect and its surroundings, IR camera performance parameters [2], thermal stimulation conditions, signal processing method, along with operator experience. The defect orientation to the surface under inspection may also affect its detectability. 
Adhesive failure and/or detachment of adhered ceramic tiling are common building pathologies ([11],[12]). Bonding defects may be cause by incorrect positioning, omission of movement joints, and/or through poor adhesion of the ceramic tile cladding system [13] due to imperfections of the adhesive layer application. Bonding defects in the adhered ceramic tiling system may occur between the adhesive layer and the ceramic tile and/or between the adhesive layer and the substrate. The main causes for occurring bonding defects are the presence of water [13] and the existence of tensions, which are affected by the existence of hollow areas inside the bonding layer.

Taking into account that these durability problems represent serious risks to public safety, as tiles and concrete spalling may fall out from the external facade, preventive inspections should be performed, in order to detect potential anomalies and evaluate the conditions of the adhered ceramic tiling systems in due time.

Several authors ([11],[13],[14],[15]) have been able to detect and characterize bonding defects on adhered ceramic tiling by applying a controlled thermal load. Simões et al. [11] performed IR measurements in a set of test specimens produced with induced and non-induced defects in the adhesive layer. Test specimens surface were stimulated by two halogen lamps (with $2000 \mathrm{~W}$ each) that released a rectangular modulated heating curve. A reflection mode analysis was performed on the raw thermal images, making the detection of several type of defects possible.

$\mathrm{Li}$ et al. [13] successfully detected bonding defects (filled with air and moisture) in adhered ceramic tiling, by using IR lamps. IR images were recorded continuously within one minute intervals. During this period, the authors observed that the surface temperature of the defected region filled with air was higher than of sound areas, while in defected areas filled with water it was lower. Thus, the defect region filled with air was detectable. However, after half an hour of the cooling down process, the defect region filled with air was not detected in IR images, as it did not show a surface temperature different from the sound area. In contrast, the defect region filled with water was detectable due to higher surface temperature, since water has higher heat capacity.

Hung et al. [14] detected and characterized bonding defects in a mosaic and ceramic tile wall after an exposure period of $180 \mathrm{~s}$ to an array of IR lamps by applying transient pulse heating. The authors highlight that this thermal stimulation method is limited to bonding defects close to the surface, since the energy delivered by the stimulation source is not sufficient for deep defect inspection of ceramic materials.

Finally, Sfarra et al. [15] applied a rectangular pulse through PT method to stimulate a green ceramic tile by using two flash lamps, in either transmission (i.e. thermal waves is delivered to one side of the surface while recording from the opposite side) or reflection mode. The authors were able to detect subsurface induced defects (such as plastic, aluminum, wood, sponge filled with air), and also, non-induced ones (such as cracks), by recording the cooling down process. Defect areas appeared at higher or lower surface temperature than sound areas, depending on the thermal properties of both the material (i.e. sound area) and the defect.

It has been shown that active thermography can be used as a diagnostic tool to detect bonding defects, particularly the ones that do not present pathologies at the surface at the time of the inspection. Also it can provide essential and accurate information for maintenance and repair. However, studies on bonding defects of ceramic tiling are still limited in number [12], particularly considering the number of parameters that may be involved in active thermography applications, such as defect geometry and depth, signal processing methods, and others.

In this context, the main purpose of this paper is to assess the feasibility of applying the active thermography technique in adhered ceramic tiling systems to evaluate bonding defects present either between the adhesive layer and the ceramic tile and/or between the adhesive layer and the substrate. For this purpose, an experimental assessment of the thermal stimulation conditions involved in a rectangular modulated heating curve (i.e. number of heating periods, heating time and the available heating power) when applying an optical heat source, and of the data analysis methods available (Automation Technology software), which allow extracting the phase and/or amplitude of the modulation, is carried out, in order to establish an effective and efficient experimental procedure.

In order to accomplish this, a set of test specimens were constructed with artificial defects in the adhesive layer. The test specimens were subjected to various thermal stimulation conditions and the resulting raw thermal images were processed with the data analysis methods available in the software.

\section{Test specimens and equipments}

A set of test specimens with artificial bonding defects in the adhesive layer of the ceramic tiling were constructed using dense cement wood boards as a substrate, cementations adhesive mortar as the adhesive layer and ceramic tiles $9 \mathrm{~mm}$ thick, with $31,5 \times 31,5 \mathrm{~cm}^{2}$ or $33,5 \times 33,5 \mathrm{~cm}^{2}$, and with an orange or black finishing color. The uncoated space of the substrate board was covered on both sides with expanded polystyrene foam (EPS), in order to decrease heat losses on test specimen's surface when applying an external heating source. Figure 1 shows the schematic drawing of the experimental set-up used in laboratory IR measurements.

Defects were induced by including various materials with different dimensions and depths in the adhesive layer (table 2), in order to represent bonding defects inside the ceramic tile system, such as air spaces and partial detachment of the adhesive layer. To create the induced air cavities, a polymer box was applied. The partial detachment of the adhesive layer was performed by applying an acetate sheet with demoulding oil on the tile bed surface before the ceramic tile application. When the curing time ended, the acetate sheet was removed creating an induced partial detachment of the adhesive layer. Extruded polystyrene foam (XPS) and natural cork materials were also used to simulate defects. Except for the partial detachment defect of the adhesive layer, the materials used for defect simulation were left inside the tile bed. 
After the infrared (IR) measurements, the ceramic tiles were removed in order to measure defect depth using an electronic caliper rule. Three measurements were made to each geometric figure side, resulting in the values of average depth of the artificial defect (table 2).

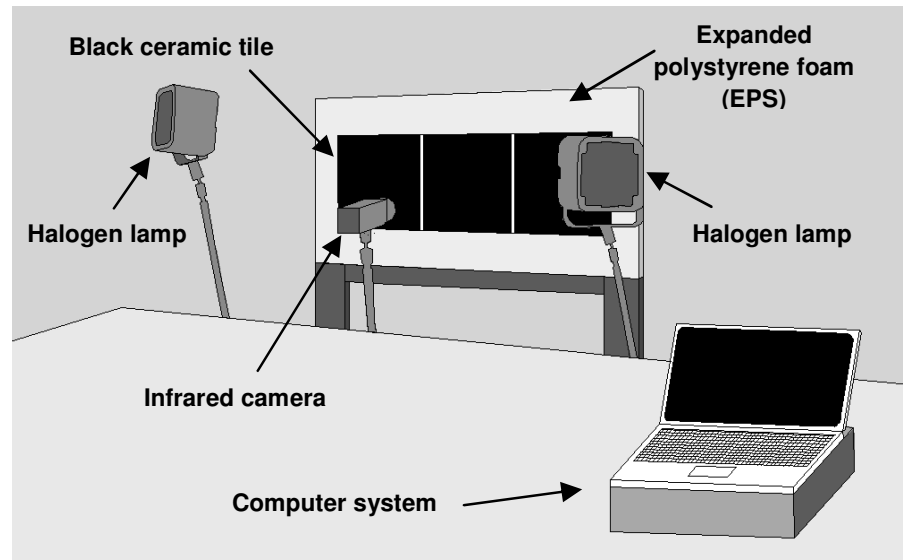

Fig. 1. Schematic drawing of the experimental set-up for infrared (IR) measurements: a computer system, a test specimen coated with tree ceramic tiles and expanded polystyrene foam (EPS), and an IR camera and two halogen lamps in reflection mode.

Table 2. Induced defect characteristics performed in the adhesive layer of the test specimens.

\begin{tabular}{|c|c|c|c|c|c|c|c|}
\hline \multicolumn{8}{|c|}{ Induced defects characteristics } \\
\hline Material & \multicolumn{2}{|c|}{ Polymer box } & \multicolumn{2}{|c|}{$\begin{array}{c}\text { Extruded } \\
\text { polystyrene foam } \\
\text { (XPS) }\end{array}$} & \multicolumn{2}{|c|}{ Natural cork } & $\begin{array}{l}\text { Acetate sheet with } \\
\text { demoulding oil }\end{array}$ \\
\hline Defect & \multicolumn{2}{|c|}{ Air space } & \multicolumn{2}{|c|}{ Material inclusion } & \multicolumn{2}{|c|}{ Material inclusion } & $\begin{array}{c}\text { Partial detachment } \\
\text { between the adhesive }\end{array}$ \\
\hline Number per specimen & 1 & 2 & 1 & 2 & 1 & 1 & 1 \\
\hline Area $\left(\mathrm{cm}^{2}\right)$ & $12 \times 3$ & $2,5 \times 2,5$ & $12 \times 3$ & $2,5 \times 2,5$ & $3^{2} x \pi$ & $7,5 \times 7,5$ & $15 \times 33,5$ \\
\hline Thickness (mm) & 3 to 4 & 3 to 4 & 3 to 4 & 3 to 4 & 4 to 5 & 4 to 5 & 0,09 \\
\hline Average depth ${ }^{(1)}(\mathrm{mm})$ & 3,3 & 3,3 and 3,4 & 2,3 & 1,9 and 2,4 & 2,5 & 2,8 & 0 \\
\hline
\end{tabular}

${ }^{(1)}$ Thickness of the adhesive layer above the defect surface.

A sound test specimen, i.e. without defects in the adhesive layer, was also prepared. When applying ceramic tile onsite, frequently the adhesion properties of the adhesive layer are enhanced by strikethrough the tile bed surface. In this context, strikethrough was performed on the tile bed surface of the sound test specimen using a serrated trowel. After the ceramic tile was removed, the measurement of the depth of the strikethrough revealed to have an average of $3,2 \mathrm{~mm}$ (by measuring twelve depth values).

The IR measurements were performed with the software IR-NDT version 1.74 from Automation Technology (linked to a computer system) and using an IR camera (model A615 from FLIR Systems). The values of the parameters of the IR camera used are the following: a spectral range of 7,5-14 $\mu \mathrm{m}$, a field of view of $25^{\circ} \times 19^{\circ}$, a spatial resolution of $0,68 \mathrm{mrad}$, a focal length of $24,6 \mathrm{~mm}$, an IR detector with $640 \times 480$ pixels resolution, a thermal sensitivity lower than $0,05^{\circ} \mathrm{C}$ at $30^{\circ} \mathrm{C}$, and a temperature accuracy of $\pm 2^{\circ} \mathrm{C}$ or $2 \%$. The IR measurements performed inside a laboratory with controlled ambient temperature $\left(23 \pm 2^{\circ} \mathrm{C}\right)$ and relative humidity $(50 \pm 5 \%)$.

\section{Experimental procedure assessment}

In order to propose an effective and efficient experimental procedure for bonding defects evaluation, i.e. defect detection and characterization, in adhered ceramic tiling using active infrared (IR) thermography, the experimental procedure was assessed in two steps. Firstly the thermal stimulation conditions on test specimen's surface involving a rectangular modulated heating curve were assessed, particularly the number of heating periods, the heating time and the available heating power released from halogen lamps. Secondly, based on the previous step, the methods available on the Automation Technology software were applied to analyse the results. These allow extracting phase and/or amplitude results from the raw thermal images gathered during the measurements. The methods available on this software are the 
following: pulse phase evaluation algorithm, lock-in harmonic approximation algorithm, lock-in single frequency and lock-inRef harmonic signal algorithm.

In each experiment, a video of $270 \mathrm{~s}$ was recorded by the IR camera placed perpendicularly to the ceramic tile surface. The video duration includes the heating period and the beginning of the cooling down process. The acquisition frequency was $6,25 \mathrm{~Hz}$. The transient thermal gradient was produced on test specimens' surface using a rectangular modulated heating curve produced by two halogen lamps ( $2500 \mathrm{~W}$ each), that were placed on the same side as the IR camera (i.e. reflection mode). The distance from the surfaces under inspection to the IR camera and the halogen lamps was less than $1 \mathrm{~m}$.

Based on ASTM E 1862-97 [16], in order to compensate the reflections on the ceramic tile surface from its surroundings, the reflected temperature was estimated by placing a crumpled up piece of aluminium foil on the surface and by measuring the average temperature of the foil target, with emissivity set to one. The software used to estimate the reflected temperature was IRControl version 4.59 from Automation Technology.

After the calibration of the software (IRControl version 4.59) with the reflected temperature value, the target thermal emissivity was measured, based on ASTM E 1933-99a [17]. A black tape with known emissivity $(\varepsilon=0,95)$ was placed on the surface under inspection. After the emissivity value of the black tape was set on the software, its surface temperature was obtained. The target thermal emissivity was found by varying the emissivity value on the software until the temperature of the ceramic tile surface was equal to the known tape surface temperature. The thermal emissivity obtained for orange and black finishing ceramic tiles was 0,92 and 0,95 respectively.

Both the reflected temperature and the target thermal emissivity, were measured in the software IRControl version 4.59 and set on the software IR-NDT version 1.74 before performing each of the IR measurements, in accordance with the procedures described above.

\subsection{Thermal stimulation conditions for a rectangular modulated heating curve}

To evaluate the number and the duration of the heating periods, as well as the heating power released from the halogen lamps (in this sequence), a rectangular heating curve was assumed and the signal was processed using the pulse phase evaluation algorithm. The infrared (IR) measurements were performed with at least $24 \mathrm{~h}$ between them, to guarantee that the energy equilibrium with the surrounding environment was reached.

Table 3 presents the combination of parameters considered for the tests of the thermal stimulation conditions. The number of heating periods was evaluated assuming a maximum duration of $60 \mathrm{~s}$. All IR tests performed allowed to detect the defects, but the ones using one heating period showed better phase contrast between the defected and the sound areas, which enhanced defect detectability. The IR image from $120 \mathrm{~s}$ of heating showed better phase contrast. The variation of the available heating power (i.e. $5000 \mathrm{~W}$ ) was then studied considering only one heating period with a duration of $120 \mathrm{~s}$. The results confirmed that the use of $100 \%$ of the available heating power released from the halogen lamps allowed for better IR image results.

Table 3. Evaluation of the thermal stimulation conditions for a rectangular modulated heating curve.

\begin{tabular}{|c|c|c|c|c|c|c|c|c|}
\hline \multirow{2}{*}{\multicolumn{2}{|c|}{$\begin{array}{l}\text { Thermal stimulation conditions for a } \\
\text { rectangular modulated heating curve }\end{array}$}} & \multicolumn{7}{|c|}{ Heating time (s) } \\
\hline & & 15 & 20 & 45 & 60 & 90 & 120 & 150 \\
\hline \multirow{2}{*}{$\begin{array}{c}\text { Number of heating } \\
\text { periods }\end{array}$} & 1 & - & - & $x$ & $x$ & $x$ & $x$ & $x$ \\
\hline & 3 & $x$ & $x$ & - & - & - & - & - \\
\hline \multirow{3}{*}{$\begin{array}{l}\text { Available heating } \\
\text { power (\%) }\end{array}$} & 50 & - & - & - & - & - & $x$ & - \\
\hline & 80 & - & - & - & - & - & $x$ & - \\
\hline & 100 & $x$ & $x$ & $x$ & $x$ & $x$ & $x$ & $x$ \\
\hline
\end{tabular}

According to the results obtained from thermal simulation conditions assessment, the procedure proposed for a rectangular modulated heating curve using active thermography technique is one period of $120 \mathrm{~s}$ of heating, followed by $150 \mathrm{~s}$ of cooling, for an acquisition frequency of $6,25 \mathrm{~Hz}$, using the total heating power from the lamps $(5000 \mathrm{~W})$. Figure $2 \mathrm{~b}$ shows a phase image that resulted from the application of the proposed procedure, where the induced defects are detectable. Figure $2 \mathrm{a}$ shows the position and size of the defects made of thin natural cork pieces. They are beneath the adhesive layer between $2,5 \mathrm{~mm}$ and $2,8 \mathrm{~mm}$ for the circular $\left(3^{2} \mathrm{x} \pi \mathrm{cm}^{2}\right)$ and square $\left(7,5 \mathrm{x} 7,5 \mathrm{~cm}^{2}\right)$ defects, respectively. The ceramic tile is $9 \mathrm{~mm}$ thick, which means that the defects are about 10,5 mm distanced from surface. Furthermore, some non-induced defects were also detected (figure $2 b$ ), which were later confirmed after removing the ceramic tile (figure 2c). The non-induced defect areas represent air gaps with less than $1 \mathrm{~mm}$. 
a

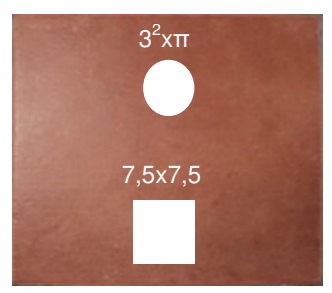

b

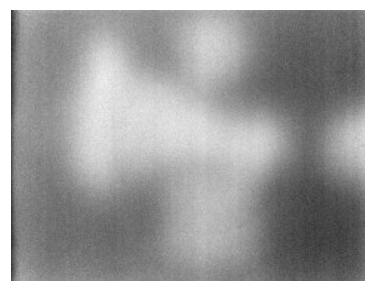

C

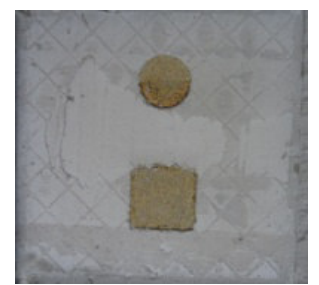

Fig. 2. Test specimen with the natural cork defects: a) schematic drawing (area defects in $\mathrm{cm}^{2}$ ); b) phase image from the pulse phase evaluation algorithm; and c) photo after the orange ceramic tile has been removed.

(Infrared image with (b) a phase scale of 1,254 - black to 1,296 - white)

\subsection{Data analysis methods for phase and/or amplitude modulation}

The software IR-NDT version 1.74 provides various data analysis methods to process the resulting raw thermal images from infrared (IR) measurements by extracting the phase and/or amplitude of the modulation. Considering the procedure proposed for the thermal simulation conditions, IR measurements were performed and each one of these signal processing algorithms were applied to the raw thermal images, in order to efficiently enhance bonding defect detectability and characterization. This paper only includes results from the pulse phase evaluation algorithm and lock-in harmonic approximation algorithm.

Figure 3 shows the test specimen results with the extruded polystyrene (XPS) defects. Along with the induced XPS defects that can be reasonably detected in the raw thermal image (figure $3 \mathrm{~b}$ ), several non-induced defects were also detected and confirmed after removing the ceramic tile (figure $3 \mathrm{e}$ ). The non-induced defects identified in figure $3 \mathrm{e}$ revealed to be air gaps with thickness of less than $1 \mathrm{~mm}$. The cracks observed in the adhesive layer of figure $3 e$ resulted from removing the ceramic tile.

In figure $3 \mathrm{~b}$, the areas with defect shown in light color correspond to high temperatures (for a grey scale). The presence of the XPS defects and the air gaps in the adhesive layer interfered with the heat flow acting as a barrier for heat propagation, resulting in local surface temperature variations over time. The raw thermal image presented in figure $3 \mathrm{~b}$ corresponds to the last one of the resulting image sequence from IR measurement, which demonstrated the better thermal contrast between defect and sound areas.

Figures $3 c$ and $3 d$, that correspond to phase and amplitude images, respectively, resulted from the application of signal processing algorithms. It is visible that the application of the signal processing algorithms enhanced bonding defect detectability and characterization, when compared with the raw thermal image (figure 3b). However, it may also be seen that some signal processing algorithms performed better than others.

a

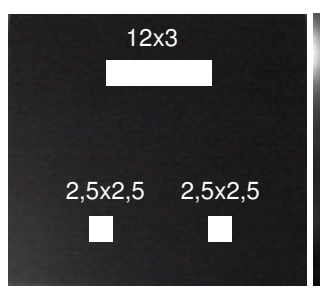

b

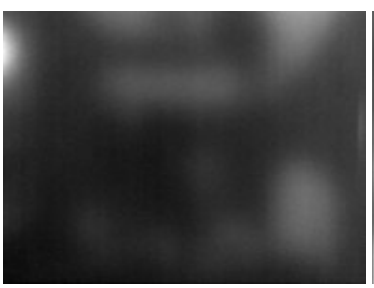

C

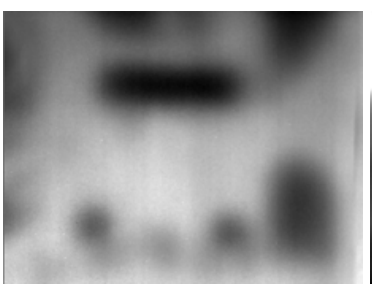

d

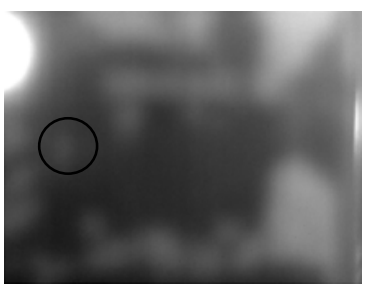

e

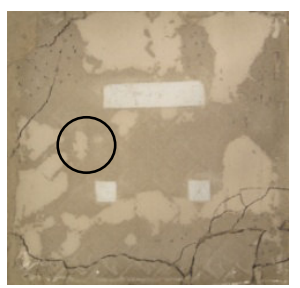

Fig. 3. Test specimen with the extruded polystyrene (XPS) defects: a) schematic drawing (area defects in $\mathrm{cm}^{2}$ );

b) raw thermal image; c) phase image from the pulse phase evaluation algorithm; d) amplitude image from Lock-in harmonic approximation algorithm; and e) photo after the black ceramic tile has been removed.

(Infrared images with (b) a temperature scale $\left({ }^{\circ} \mathrm{C}\right.$ ) of 27,6 - black to 34,1 - white; (c) a phase scale of -1,824 - black to -0,701-white; and (d) an amplitude scale of 69,23 - black to 400,11 - white)

Figure $3 c$ shows a phase image that resulted from the application of the pulse phase evaluation algorithm. From the range of the available algorithms that provides phase images, this algorithm revealed to be one of the most suited to get the best contrasts ensuring defect detection. In the phase image (figure 3c) is visible that, among the induced defects, the rectangular defect with $12 \times 3 \mathrm{~cm}^{2}$ shows a better phase contrast than the square defects with $2,5 \times 2,5 \mathrm{~cm}$. This contrast difference is due to defects area $\left(12 \times 3 \mathrm{~cm}^{2}\right.$ versus $\left.2,5 \times 2,5 \mathrm{~cm}^{2}\right)$, considering that the average depth of the adhesive layers is similar (table 2).

The figure $3 d$ shows an amplitude image from the application of the lock-in harmonic approximation algorithm, considering that all of the available algorithms tested for amplitude modulation presented similar results. Based on figure $3 e$, particularly the non-induced defects located between the square induced defects $\left(2,5 \times 2,5 \mathrm{~cm}^{2}\right)$ are much more detectable in the amplitude image (figure $3 \mathrm{~d}$ ) than in the phase image (figure 3c). Furthermore, the non-induced defect 
that is highlighted by a circle in figure $3 e$ is detected in the amplitude image (figure 3d), but is not detected in the phase image (figure $3 c$ ). However, in amplitude images and raw thermal images, the lamp reflection was always visible (figures $3 \mathrm{a}$ and $3 \mathrm{~d}$, in the upper left corner), which may affect IR image interpretation. In figure $3 \mathrm{~d}$, the lamp reflection is brighter than in figure $3 a$, due to the modification of the contrast scale in the software, in order to improve defect detectability.

The test specimen with the polymer box defects (figure 4) revealed to have a behaviour similar to the test specimen with the XPS defects, i.e. induced and non-induced (air gaps with thickness of less than $1 \mathrm{~mm}$ ) defects detection and characterization enhanced with pulse phase evaluation algorithm. However, the results of this test specimen (figure 4d) allow the distinction between induced and non-induced defects, i.e. defects with different thermal properties, such as polymer boxes and air gaps. Additionally, IR camera reflection is only visible in the IR raw thermal image (identified with a triangle in figure $4 \mathrm{~b}$ ).

a

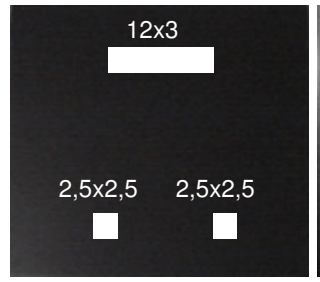

b

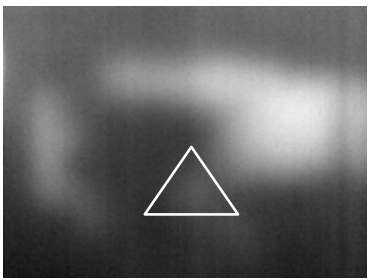

C

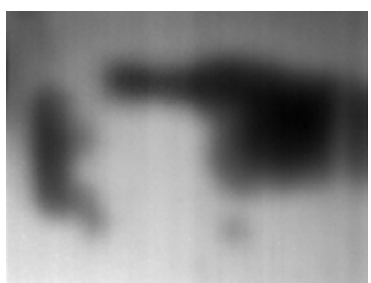

d

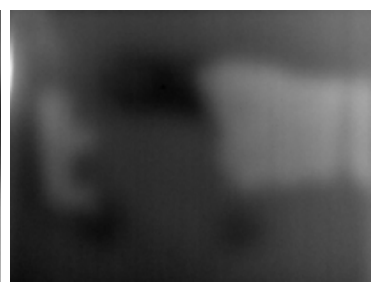

e

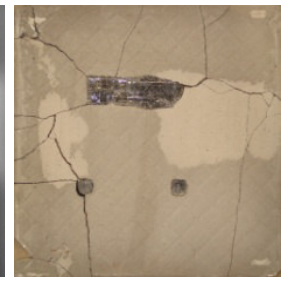

Fig. 4. Test specimen with the polymer box defects: a) schematic drawing (area defects in $\mathrm{cm}^{2}$ ); $b$ ) raw thermal image; c) phase image from the pulse phase evaluation algorithm; d) amplitude image from Lock-in harmonic approximation algorithm; and e) photo after the black ceramic tile has been removed.

(Infrared images with (b) a temperature scale $\left({ }^{\circ} \mathrm{C}\right.$ ) of 28,7 - black to 32,6 - white; (c) a phase scale of -1,552 - black to -0,041-white; and (d) an amplitude scale of 105,13 - black to 384,71 - white)

Figure 5 shows the results of the test specimen with partial detachment between the adhesive layer and the ceramic tile. Along with the detection of the induced and non-induced partial detachment in phase image (figure 5c), based on figures $5 \mathrm{a}$ and $5 \mathrm{e}$, the phase image shows a clear contrast between defect and sound areas, not being influenced by the reflection in the upper left corner, visible on figures $5 \mathrm{~b}$ and $5 \mathrm{~d}$. The non-induced defects revealed to be a hollow area with thickness of less than $1 \mathrm{~mm}$ (figure $5 \mathrm{e}$ ).

a

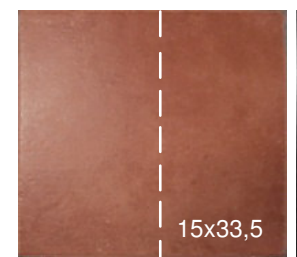

b

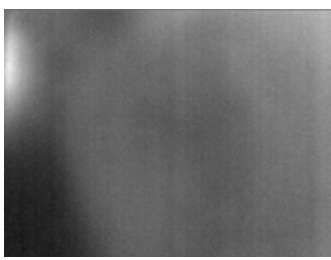

C

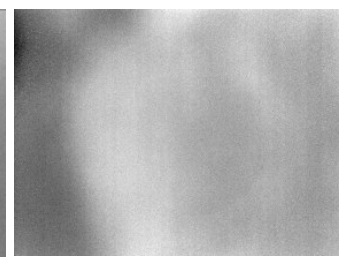

d

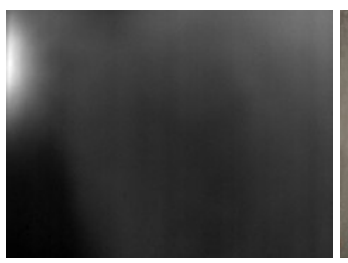

e

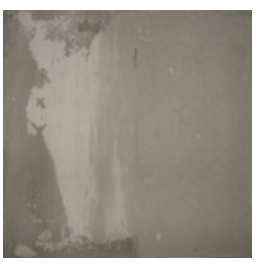

Fig. 5. Test specimen with the partial detachment between the adhesive layer and the ceramic tile: a) schematic drawing (area defect in $\mathrm{cm}^{2}$ ); b) raw thermal image; c) phase image from the pulse phase evaluation algorithm; d) amplitude image from Lock-in harmonic approximation algorithm; and e) photo after the orange ceramic tile has been removed.

(Infrared images with (b) a temperature scale $\left({ }^{\circ} \mathrm{C}\right)$ of 25,8 - black to 28,9 - white; (c) a phase scale of 1,352 - black to 1,427 - white; and (d) an amplitude scale of 0,15 - black to 448,41 - white)

The IR images sequences revealed that the light colored areas either correspond to defect areas (e.g. figure $2 b$, $5 \mathrm{c}$ ) or sound areas (e.g. figures $3 \mathrm{c}, 4 \mathrm{c}$ ), in phase images (for a grey scale). While in amplitude images, generally light colored areas correspond to defect areas (e.g. figures $3 d, 5 d$, and the air spaces in figure 4d).

Figure 6 shows results obtained from a specimen without bonding defects. The raw thermal image (figure 6b), phase image (figure 6c), and amplitude image (figure 6d) evidence that when applying the active IR thermography through the proposed thermal stimulation procedure, the strikethrough made on the tile bed surface oriented perpendicularly to the surface and with a width around $5 \mathrm{~mm}$ is not detectable. Again, lamp reflection is seen in raw thermal images and amplitude images (figures $6 \mathrm{~b}$ and $6 \mathrm{~d}$, respectively, in the upper left corner). Note that some parts of the tile bed that do not appear in figure 6 e remained bonded to the ceramic tile. 
a

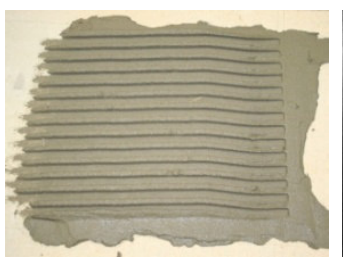

b

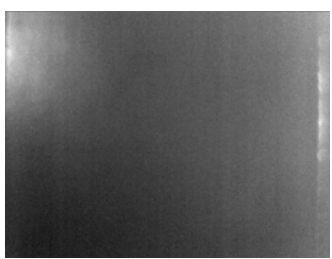

C

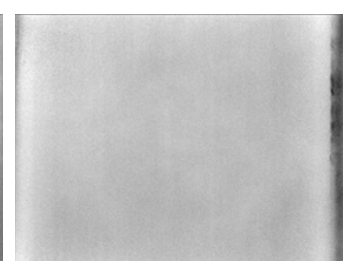

d

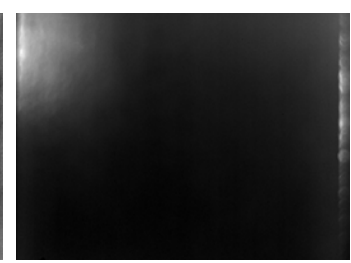

e

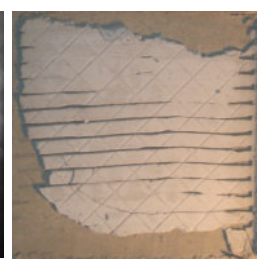

Fig. 6. Sound test specimen: a) photo of the strikethrough tile bed surface before orange ceramic tile application; b) raw thermal image; c) phase image from the pulse phase evaluation algorithm; d) amplitude image from Lock-in harmonic approximation algorithm; and e) photo after the orange ceramic tile has been removed. (Infrared images with (b) a temperature scale $\left({ }^{\circ} \mathrm{C}\right.$ ) of 26,1 - black to 29,1 - white; (c) a phase scale of 1,368 - black to 1,457 - white; and (d) an amplitude scale of 29,43 - black to 399,64 - white)

\section{Conclusions}

This paper intended to determine the feasibility of using the active thermography technique to detect and characterize bonding defects in adhered ceramic tiling and propose an experimental procedure. For this purpose, an experimental assessment of the several parameters associated with using an external heating source in civil engineering was carried out. The parameters analysed were the thermal stimulation conditions involved in a rectangular modulated heating curve (i.e. number and duration of heating periods and the available heating power) when applying an optical heat source. The data was analysed by applying the methods available on the Automation Technology software, which allows the extraction of phase and/or amplitude of modulation. Furthermore, defect geometry (area and thickness) and depth were also analysed.

The application of the proposed experimental procedure for using active thermography in adhered ceramic tiling allowed the detection and characterization of bonding defects. In this paper the following experimental procedure was defined: application of thermal simulation following one rectangular heating curve with $120 \mathrm{~s}$, followed by $150 \mathrm{~s}$ of cooling; the acquisition frequency was defined at $6,25 \mathrm{~Hz}$; the heating power released from two halogen lamps is $5000 \mathrm{~W}$; measurements with the infrared (IR) camera were in reflection mode. The data processing with the pulse phase evaluation algorithm allowed the improvement of the feasibility of bonding defect detection and characterization.

Following this procedure, defects between the adhesive layer and the ceramic tile were identified, e.g. air gaps with thickness of less than $1 \mathrm{~mm}$ at $9 \mathrm{~mm}$ depth from the ceramic tile surface or a partial detachment with thickness of less than $1 \mathrm{~mm}$. Additionally, defects between the adhesive layer and the substrate were also analyzed, e.g. induced air cavities with 2,5x2,5 $\mathrm{cm}^{2}$, with a thickness of about 3 to $4 \mathrm{~mm}$, placed at a depth of around 12,5 mm from the surface. Moreover, strikethrough performed on the tile bed surface oriented perpendicularly to the surface with a maximum width of $6 \mathrm{~mm}$ and a $3,2 \mathrm{~mm}$ average depth had no effect on the thermal stimulation applied to the surface.

\section{Acknowledgements}

The research work presented herein was supported by FEDER funds through the Operational Programme for Competitiveness Factors - Compete and by national funds through the FCT - Portuguese Foundation for Science and Technology, under research project PTDC/ECM/114189/2009 and was supported in part by QREN - Compete under the research project Active Floor Project (FCOMP-01-0202-FEDER-021583. This work has also been supported by the Energy and Mobility for Sustainable Regions - EMSURE - Project (CENTRO-07-0224-FEDER-002004).

\section{REFERENCES}

[1] Maldague X., "Theory and practice of infrared technology for non-destructive testing", pp. 1-618, John Wiley \& Sons, 2001.

[2] Vollmer M., Mollmann K.-P., "Infrared thermal imaging. Fundamentals research and applications", pp. 1-593, Wiley-VCH Verlag GmbH \& Co. KGaA, 2010.

[3] Schlichting J., Maierhofer Ch., Kreutzbruck M., "Defect sizing by local excitation thermography". Proceedings of 10th Quantitative InfraRed Thermography conference, Québec (Canada), 2010.

[4] Meola C., "Origin and theory of infrared thermography" in Meola C. - "Infrared thermography recent advances and future trends", pp. 3-28, Bentham Science Publishers, 2012.

[5] Balaras C. A., Argiriou A. A., "Infrared thermography for building diagnostics". Energy and Buildings, vol. 34, pp. 171-183, 2002.

[6] Ibarra-Castanedo C., Tarpani J. R., Maldague X. P. V., "Nondestructive testing with thermography". European Journal of Physics, vol. 34, pp. S91-S109, 2013. 
[7] Arndt R. W., "Square pulse thermography in frequency domain as adaptation of pulsed phase thermography for qualitative and quantitative applications in cultural heritage and civil engineering". Infrared Physics \& Technology, vol. 53, pp. 246-253, 2010.

[8] Plesu R., Teodoriu G., Tãranu G., "Infrared thermography applications for building investigation". Universitatea Tehnicã Gheorghe Asachi din lasi. Tomul L VIII (LXII)(1), Constructii. Arhitecturã, 2012.

[9] Rotolante R. A., "Pulse and lock-in NDT infrared active-source techniques" in Meola C. - "Infrared thermography recent advances and future trends", pp. 181-199, Bentham Science Publishers, 2012.

[10] Ibarra-Castanedo C., González D., Klein M., Pilla M., Vallerand S., Maldague X., "Infrared image processing and data analysis". Infrared Physics \& Technology, vol. 46, pp. 75-83, 2004.

[11] Simões N., Simões I., Tadeu A., Serra C., "Evaluation of adhesive bonding of ceramic tiles using active thermography", Proceedings of 11th Quantitative InfraRed Thermography conference, paper QIRT2012-362, Naples (Italy), 2012.

[12] Edis E., Flores-Colen I., de Brito J., "Passive thermographic inspection of adhered ceramic claddings: limitation and conditioning factors". Journal of Performance of Constructed Facilities, vol. 27(6), pp. 737-747, 2013.

[13] Li Z., Yao W., Lee S., Lee C., Yang Z., "Application of infrared thermography technique in building finish evaluation". Journal of Nondestructive Evaluation, vol. 19(1), pp. 11-19, 2000.

[14] Hung Y. Y., Chen Y. S., Ng S. P., Liu I., Huang Y. H., Luk B. L., Ip R. W. L., Wu C. M. L., Chung P. S., "Review and comparison of shearography and active thermography for nondestructive evaluation". Materials Science and Engineering R, vol. 64, pp. 73-112, 2009.

[15] Sfarra S., Ibarra-Castanedo C., Lambiase F., Paoletti D., Di llio A., Maldague X., "From the experimental simulation to integrated non-destructive analysis by means of optical and infrared techniques: results compared". Measurement Science and Technology, vol. 23, pp. 14, 2012.

[16] ASTM E 1862-97, "Standard test methods for measuring and compensating for reflected temperature using infrared imaging radiometers". American Society for Testing and Materials, Pennsylvania (USA), 2002.

[17] ASTM E 1933-99a, "Standard test methods for measuring and compensating for emissivity using infrared imaging radiometers". American Society for Testing and Materials, Pennsylvania (USA), 2010. 